Kyoto University,

Graduate School of Economics

Discussion Paper Series

Rules of Origin and Technology Spillovers from Foreign Direct Investment under International Duopoly

Naoto JINJI and Yoshihiro MIZOGUCHI

Discussion Paper No. E-15-012

Graduate School of Economics Kyoto University

Yoshida-Hommachi, Sakyo-ku

Kyoto City, 606-8501, Japan

December, 2015 


\title{
Rules of Origin and Technology Spillovers from Foreign Direct Investment under International Duopoly ${ }^{*}$
}

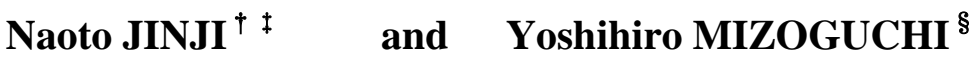

\begin{abstract}
Using a simple three-country model of international duopoly, this study analyses the optimal choice of rules of origin (ROO) in a free trade area/agreement (FTA) when firms from outside the FTA must undertake foreign direct investment (FDI) in FTA countries and conduct part of their production process within the FTA to comply with the ROO. FDI causes spillovers of the superior production technology from a non-FTA firm to its competitor within the FTA, depending on how much of the production process is shifted to the FTA area. In this situation, we show that as the degree of multilateral trade liberalisation before formation of the FTA is higher, the optimal ROO tends to be less stringent.
\end{abstract}

Keywords: rules of origin; free trade area/agreement; foreign direct investment; technology spillovers; oligopoly

JEL Classification: F12; F15

\footnotetext{
* We thank Yasuhiro Arai, Keisuke Hattori, Keisaku Higashida, Yukiko Ito, Fukunari Kimura, Tomohiro Kuroda, Hiroshi Mukunoki, Tetsuya Saito, Morihiro Yomogida, and participants of the Kanto Branch Workshop of the Japan Society of International Economics, the 5th HITS-MJT Seminar on International Economy and Industry, and the 2015 Spring meeting of the Japanese Economic Association for their helpful comments and suggestions on earlier versions of the paper. Jinji acknowledges financial support from the Japan Society for the Promotion of Science under the Grant-in-Aid for Scientific Research (B) Nos. 23330081 and 23330087 and the Grant-in-Aid for Challenging Exploratory Research No. 25590057. The authors are solely responsible for any remaining errors.

${ }^{\dagger}$ Corresponding author. Faculty of Economics, Kyoto University, Yoshida-honmachi, Sakyo-ku, Kyoto 606-8501, Japan. Phone\& fax: +81-75-753-3511. E-mail: jinji@econ.kyoto-u.ac.jp

${ }^{\ddagger}$ Research Institute of Economy, Trade and Industry (RIETI), Tokyo, Japan.

${ }^{\S}$ Department of Regional Economics, Teikyo University, 1-1 Toyosatodai, Utsunomiya, Tochigi 320-8551, Japan. E-mail: ymizogu@gmail.com
} 


\section{INTRODUCTION}

Free trade areas/agreements (FTAs), which are currently the most popular form of the regional trade agreements (RTAs), usually specify rules of origin (ROO) to cope with the issue of so-called "tariff circumvention." Unlike the case of customs unions, in which common external tariffs have to be chosen by member countries, members of an FTA can choose their own external tariffs. Consequently, when goods from non-member countries are exported to high-tariff member countries' markets, it is possible to avoid paying these high tariffs by first exporting the goods to a member country that imposes a lower tariff and thereafter re-exporting the goods with tariff-free within the FTA to the target market where tariffs are high. ROO prevent such "tariff circumvention" by specifying detailed conditions that have to be satisfied for goods to be eligible for tariff-free transactions among members of the FTA.

ROO usually require a certain amount of actual processing to be undertaken within the FTA for qualification of goods as produced within the FTA. Whereas ROO are a legitimate policy for FTA members not to lose the benefits of belonging to the FTA, they have sometimes been criticized as a tool of potentially disguised protectionism (Krueger, 1999; Krishna \& Krueger, 1995).

However, the opposite view can be considered wherein ROO serve as a means for FTA member countries to attract foreign direct investment (FDI) by firms from non-FTA countries. In other words, establishing appropriate ROO may successfully induce firms from non-FTA countries to comply with the ROO by entering the FTA via FDI. Indeed, it is up to the firms from non-member countries to decide whether to initiate an FDI in an FTA country. A major motivation for firms from non-member countries to comply with ROO through FDI to establish production operations in an FTA member country is the so-called "tariff jumping," i.e., avoiding paying high tariffs imposed on imported goods by supplying goods from the plant established within the country in which the market is located. If it is beneficial for the member countries' economy to receive FDI from non-member countries, then the FTA members' governments can consider a policy measure of establishing ROO that induce FDI from non-member countries. 
In which situations does FDI from non-member countries benefit the economies of FTA members? First, FDI can have the positive effect of creating new jobs in member countries. This positive effect is most pronounced when FDI takes the form of green field investment. Second, upstream industries can benefit as FDI boosts their demand by increasing the demand for raw materials and intermediate goods produced in the FTA country. Third, if firms in non-member countries possess superior production technology than that of firms in members, FDI may cause technology spillovers from external firms to internal firms. Of these three effects, we focus on the technology spillovers through FDI. There have been a number of previous studies regarding the effects of FDI by multinational corporations on local firms' productivity. For example, Haskel et al. (2007) use data from the United Kingdom (UK) to show that a positive correlation exists between the market share of multinational corporations and local firms' total factor productivity (TFP), whereby a 10\% increase in the UK market share of foreign firms causes a 0.5\% rise in UK firms’ TFP. Keller and Yeaple (2009) show that $14 \%$ of the productivity improvements achieved by American manufacturers between 1987 and 1996 could be attributed to technology spillovers from FDI. Keller (2004) provides a survey of the literature on the positive (spillover) effects exercised by multinational corporations on local firms’ productivity. However, to our knowledge, few studies have analysed technology spillovers in relation with ROO of FTAs. Therefore, we examine how ROO will be chosen when FDI is expected to result in technology spillovers from non-member countries’ firms to member countries’ firms.

To accomplish this task, we employ a simple three-country model with international duopoly, in which one firm from a member of an FTA and one firm from a non-member country produce a homogeneous good and supply their goods to the market in an FTA country. ROO are set by the members of the FTA to maximise their joint welfare at the beginning of the game. After the establishment of the ROO, the government of an importing country within the FTA chooses its external tariff rate that is imposed on imports with no compliance of the ROO. The maximum external tariff rate may be restricted by multilateral trade liberalisation in prior to the FTA formation.

The main results of this study are as follows. If there were no tariff restrictions before the FTA was formed, the most stringent ROO is imposed, which would require the entire production process to be conducted within the FTA area, and the non-FTA 
firm would comply with the ROO despite the FDI leading to perfect spillovers of its superior technology to the FTA firm. Conversely, if multilateral negotiation for trade liberalisation had been concluded before the FTA was formed, which restrict the maximum level of tariffs, the optimal ROO becomes lower than the most stringent level. Our analysis predicts a negative correlation between the degree of multilateral trade liberalisation in prior to formation of the FTA and the stringency of ROO in the FTA.

Although there are a number of previous studies that are related to this study, our study differs from these existing studies. ${ }^{1}$ Ishikawa et al. (2007) analyse a final good market and show that because of price discrimination in the FTA markets for final goods, the effects of the ROO on welfare of the FTA countries depend on both the effect of preventing tariff circumvention and the effect of price discrimination in final good markets. However, Ishikawa et al. (2007) do not consider FDI by firms outside the FTA. Mukunoki (2013) investigates the effects of ROO on FDI patterns. He demonstrates the possibility that ROO enable the formation of FTAs which had not been previously possible and market-oriented FDI will switch over to export-based FDI. However, he does not consider technology spillovers through FDI. Moreover, as in this study, Chang and Xiao (2013) analyse the optimal choice of ROO and external tariffs. However, a key difference between their study and ours is that in their analysis external firms have no option to comply with the ROO. Finally, Jinji and Mizoguchi (2015) also examine the optimal ROO and external tariffs in the three-country model with international duopoly. However, their model does not consider technology spillovers from the external firm to the internal firm.

The remainder of this paper is organised as follows. Section 2 sets up the model. Section 3 shows the conditions prior to formation of the FTA as a benchmark. Section 4

\footnotetext{
${ }^{1}$ In addition to the studies mentioned in the main text, the literature of ROO also includes Falvey and Reed (2002), Ju and Krishna (2005), Lopez-de-Silanes et al. (1996), and Takauchi (2011). However, these studies do not address the issue that we analyse in this paper. Local content requirement (LCR), or domestic content protection policy, is quite similar to ROO. Since the seminal work by Grossman (1981) there have been many studies on LCR, including Belderbos and Sleuwaegen (1997), Davidson et al. (1985), Krishna and Itoh (1988), Lahiri and Ono (1998, 2003), Qiu and Tao (2001), and Takechi and Kiyono (2003). However, the issue of technology spillovers associated with policy (ROO or LCR) has not been analysed by those studies, either.
} 
analyses market competition and the external tariffs after formation of the FTA. Section

5 elaborates the optimal ROO and technology spillovers in equilibrium. Section 6 examines how the results in the previous sections will change if the maximum level of tariffs is restricted before formation of the FTA. Section 7 provides concluding remarks.

\section{THE MODEL}

In this section, we construct the model for our analysis. Let us consider an economy comprising three countries: A, B, and C. When countries A and B form an FTA, they are "member countries" and country C is a "non-member country." We focus on an oligopolistic industry. In this industry, two firms produce a homogenous good. One of these firms is located in country B and the other in country C. The firm located in country B is called the "internal firm" (firm I) and the firm located in country C is called the "external firm" (firm E). The output of firm I is $x$, and the output of firm E is $y$. All the production of firm I takes place in country B. On the other hand, while firm E initially produces goods at its plant in country C, it sets up a plant in country B through FDI, as will be explained below, to conduct some or all of the production process to supply goods to the market within the FTA. Moreover, as explained below, FDI will cause technology spillovers from firm E to firm I. The marginal cost of firms I and E prior to technology spillovers is $c^{I}$ and $c^{E}$, respectively. We assume that firm $\mathrm{E}$ possesses superior production technology than firm I, so that $c^{I}>c^{E}$.

For simplicity, we assume that the only market is in country A. The inverse demand function for goods in market A can be expressed as follows:

$$
p=a-(x+y),
$$

where $p$ is the price of the good, and $a>0$ is a parameter.

The government of country A imposes a specific tariff $t$ on imports of this good. After countries A and B form an FTA, tariffs on trade between the two countries are abolished, but external tariff rate $t$ is levied on imports from external countries (country C).

The FTA between countries A and B specifies an ROO with which compliance is required for goods to be qualified for tariff-free transactions. Here, we consider the 
following ROO: a good is recognized as "produced within the FTA" for which at least a given proportion $\phi \in[0,1]$ of the production process is undertaken within the FTA. Thus, the good produced by firm I automatically comply with the ROO because its entire production process is undertaken in country B (i.e., a member country). In contrast, firm E has to relocate its production process to an internal country of the FTA through FDI so that the ROO-stipulated minimum proportion of the production process is conducted within the FTA. We suppose that firm E establishes a plant in country B. ${ }^{2}$ Setting up a plant in country B entails fixed cost $F$. For simplicity, we assume that $F=0$. In addition, we assume that if firm E shifts a portion of its production process from its main plant in country $\mathrm{C}$ to a new plant in country $\mathrm{B}$, a costless technology transfer is made possible. Thus, no matter what proportion of the production process is shifted to the subsidiary in country $B$, the marginal cost of producing a final good remains unchanged at $c^{E}$.

On the other hand, firm E's relocation of some or all of the production process to a plant in country B will cause spillovers of firm E's superior technology to firm I. This technology spillovers will lower firm I's marginal costs. The degree of spillovers is expressed as $\gamma \in[0,1]$. We postulate the following relationship between the ROO and spillovers so that the degree of spillovers depends on what proportion of the production process is performed by firm $\mathrm{E}$ at its subsidiary in country $\mathrm{B}$ :

$$
\gamma=\Gamma(\phi), \quad \Gamma^{\prime}>0, \quad \Gamma(0)=0 .
$$

For simplicity, we postulate the simple function $\Gamma(\phi)=\phi$, and consider the simple relationship $\gamma=\phi$. Under this assumption, firm I's marginal cost $\tilde{c}$ after spillovers can be expressed as follows.

$$
\tilde{c}=c^{I}-\phi \Delta c,
$$

where

$$
\Delta c \equiv C^{I}-c^{E}>0
$$

\footnotetext{
${ }^{2}$ We assume that country A is not suitable for the production of goods because a large-scale plant is required for the production of this good but it is extremely difficult to acquire sufficient land in country A, or because the supply of labor is quite limited in country A, making it very costly to hire the sufficient number of workers for the production.
} 
Thus, the extent of technology spillovers depends on the cost differential $\Delta c$ between the two firms and the proportion of the production process $\phi$ that is undertaken within the FTA in accordance with the ROO. As is seen from Eq. (3), when $\phi=0, \tilde{c}=c^{I}$, no spillover occurs, and when $\phi=1$, then $\tilde{c}=c^{E}$, and firm I's marginal cost is equalised to that of firm E.

We consider the following four-stage game. In stage 1, the FTA member countries (countries A and B) set the level of ROO $\phi$ to maximise their joint welfare. In stage 2, country A establishes external tariff $t$ to maximise its own welfare under the provisions of Article XXIV of the General Agreement on Tariffs and Trade (GATT). In stage 3, firm $\mathrm{E}$ decides the amount of its production process that it will move to its subsidiary in country B. Finally, in stage 4, the two firms engage in duopolistic Cournot competition in country A. As usual, we use backward induction to solve the game for the subgame perfect Nash equilibrium (SPNE) as the solution concept.

The above game structure is employed because the level of ROO is usually determined in the process of negotiation of FTA among negotiating countries, whereas member countries of an FTA can change their individual external tariffs even after the FTA comes into force.

\section{BENCHMARK: PRE-FTA FORMATION}

First, we analyse the equilibrium before formation of the FTA as a benchmark. Before the FTA is formed, both firms have to pay the same tariff when they export to country A. Profits of firm I and firm E can be expressed as

$$
\pi^{I}=\left(p-c^{I}-t\right) x, \quad \pi^{E}=\left(p-c^{E}-t\right) y .
$$

From the first-order conditions, the output of each firm in Nash equilibrium is

$$
x_{b}=\left(a-2 c^{I}+c^{E}-t\right) / 3, \quad y_{b}=\left(a-2 c^{E}+c^{I}-t\right) / 3,
$$

where the subscript $b$ indicates equilibrium variables in the benchmark case. Define

$$
A^{E} \equiv a-c^{E}>0 .
$$

Using this definition, we rewrite equation (6) as follows:

$$
x_{b}=\left(A^{E}-2 \Delta c-t\right) / 3, \quad y_{b}=\left(A^{E}+\Delta c-t\right) / 3 .
$$


Each firm's profit in Nash equilibrium is as follows:

$$
\pi_{b}^{I}=\left(x_{b}\right)^{2}=\left(A^{E}-2 \Delta c-t\right)^{2} / 9, \quad \pi_{b}^{E}=\left(y_{b}\right)^{2}=\left(A^{E}+\Delta c-t\right)^{2} / 9 .
$$

Consumer surplus in country $\mathrm{A}$ in this case $C S^{A}$ is

$$
C S_{b}^{A}=\left(x_{b}+y_{b}\right)^{2} / 2=\left(2 A^{E}-\Delta c-2 t\right)^{2} / 18 .
$$

Country A's social welfare $W_{b}^{A}$ is defined as the sum of its consumer surplus and its tariff revenue:

$$
\begin{aligned}
W_{b}^{A} & =C S_{b}^{A}+t\left(x_{b}+y_{b}\right) \\
& =\left(2 A^{E}-\Delta c-2 t\right)^{2} / 18+t\left(2 A^{E}-\Delta c-2 t\right) / 3 .
\end{aligned}
$$

Country A's government sets its tariffs at a rate that maximises the country's social welfare. From the first-order condition, the optimal tariff rate before formation of the FTA is given by

$$
t_{b} \equiv \frac{2 A^{E}-\Delta c}{8} .
$$

Substituting Eq. (12) into Eqs. (9) and (11) and recalculating, we obtain the following pre-FTA profits of the firms and country A's social welfare under the optimal tariff:

$$
\begin{aligned}
& \pi_{b}^{I}=\frac{\left(2 A^{E}-5 \Delta c\right)^{2}}{64}, \\
& \pi_{b}^{E}=\frac{\left(2 A^{E}+3 \Delta c\right)^{2}}{64}, \\
& W_{b}^{A}=\frac{\left(2 A^{E}-\Delta c\right)^{2}}{16} .
\end{aligned}
$$

Note that $x=0$ when $\Delta c>(2 / 5) A^{E}$, so country A's optimal tariff may differ from $t_{b}$. Thus, substitute $x=0$ into the best response function obtained from the first-order condition for firm E to yield

$$
y_{b 2}=\left(A^{E}-t\right) / 2
$$

In this case, as country A's social welfare is

$$
W_{b 2}^{A}=\frac{\left(A^{E}-t\right)^{2}}{8}+t \frac{\left(A^{E}-t\right)}{2},
$$

the first-order condition yields 


$$
t_{b 2} \equiv \frac{A^{E}}{3}
$$

Substitute this into firm E's profits and country A's social welfare to yield respectively

$$
\begin{gathered}
\pi_{b 2}^{E}=\frac{\left(A^{E}\right)^{2}}{9}, \\
W_{b 2}^{A}=\frac{\left(A^{E}\right)^{2}}{6} .
\end{gathered}
$$

It should be reasonable to assume that the demand is non-negative even when only firm I supplies goods to the market, which requires $a-c^{I} \geq 0$ and equivalently $A^{E} \geq \Delta c$. Thus, we assume this holds throughout the paper.

The following lemma summarizes the above results.

Lemma 1. The optimal pre-FTA tariff levied by country $A$ is (i) $t=t_{b}$ (Eq. (12)) when $\Delta c \leq(2 / 5) A^{E}$ and (ii) $t=t_{b 2}$ (Eq. (17)) when (2/5) $A^{E}<\Delta c \leq A^{E}$. In (i), both firms produce goods in equilibrium, while in (ii) only firm E produces goods.

Note that, from Eqs. (12) and (17), it follows

$$
t_{b}-t_{b 2}=\frac{2 A^{E}-\Delta c}{8}-\frac{A^{E}}{3}=\frac{-2 A^{E}-3 \Delta c}{24}<0
$$

so $t_{b}<t_{b 2}$ holds.

\section{MARKET COMPETITION AND OPTIMAL EXTERNAL TARIFFS AFTER FORMATION OF FTA}

We next analyse the equilibrium wherein countries A and B form an FTA with ROO. ${ }^{3}$

\footnotetext{
${ }^{3}$ In our setting, country A may not have an incentive to form an FTA with country B or country C may be a better partner of FTA for country A as long as the industry on which our analysis focuses is concerned. However, we implicitly assume that country A has an incentive to form an FTA with country
} 


\subsection{The Subgame in which Firm E Exports}

First, we examine the equilibrium at stage 4 of the game in a subgame in which firm $\mathrm{E}$ decides to export goods $y$ exporting at stage 3. In this case, country A's government seeks to levy optimal external tariffs at stage 2 .

Firm E must pay external tariff $t$ when it supplies goods to country A's market by exporting, but firm I is exempt from tariffs when it supplies goods to country A's market. In this case, the profit of each firm is

$$
\pi^{I}=\left(p-c^{I}\right) x, \quad \pi^{E}=\left(p-c^{E}-t\right) y .
$$

From the first-order condition, each firm's output in Nash equilibrium at stage 4 of the game is

$$
x_{E X}=\left(A^{E}-2 \Delta c+t\right) / 3, \quad y_{E X}=\left(A^{E}+\Delta c-2 t\right) / 3,
$$

where the subscript $E X$ indicates equilibrium variables in a subgame wherein firm $\mathrm{E}$ opts to export. Each firm's profit in Nash equilibrium at stage 4 is

$$
\pi_{E X}^{I}=\left(x_{E X}\right)^{2}=\left(A^{E}-2 \Delta c+t\right)^{2} / 9, \quad \pi_{E X}^{E}=\left(y_{E X}\right)^{2}=\left(A^{E}+\Delta c-2 t\right)^{2} / 9 .
$$

In this case, country A's social welfare is given by

$$
W^{A}=C S+t \times y=\left(2 A^{E}-\Delta c-t\right)^{2} / 18+t\left(A^{E}+\Delta c-2 t\right) / 3 .
$$

In stage 2 of the game, country A's government chooses tariff rate to maximise its social welfare, so the optimal tariff is given by

$$
t_{E X} \equiv \frac{A^{E}+4 \Delta c}{11} .
$$

However, because GATT Article XXIV does not permit country A to raise its tariffs before or after the FTA's formation, when $t_{E X}$ exceeds the optimal pre-FTA tariff, the post-FTA tariff remains unchanged. From Lemma 1 in the previous section, country A's optimal pre-FTA tariff is $t=t_{b}$ when $\Delta c \leq(2 / 5) A^{E}$ and $t=t_{b 2}$ when $\Delta c>(2 / 5) A^{E}$. Solving for $t_{E X}>t_{b}$ with Eqs. (12) and (24), we obtain

B and country B is a better partner for country A because of conditions in other industries, which are outside the scope of our analysis. 


$$
t_{E X}-t_{b}=\frac{-14 A^{E}+43 \Delta c}{88},
$$

so when

$$
\Delta c>\frac{14}{43} A^{E} \approx 0.326 A^{E},
$$

then $t_{E X}>t_{b}$ holds. Next, solving for $t_{E X}>t_{b 2}$ with Eqs. (17) and (24), we obtain

$$
t_{E X}-t_{b 2}=\frac{-8 A^{E}+12 \Delta c}{33},
$$

so when

$$
\Delta c>\frac{2}{3} A^{E} \approx 0.667 A^{E}
$$

then $t_{E X}>t_{b 2}$ holds.

Now, substituting Eq. (24) into Eq. (22), we obtain each firm's profit when $t=t_{E X}$ :

$$
\begin{gathered}
\pi_{E X}^{I}\left(t_{E X}\right)=\frac{4\left(2 A^{E}-3 \Delta c\right)^{2}}{121}, \\
\pi_{E X}^{E}\left(t_{E X}\right)=\frac{\left(3 A^{E}+\Delta c\right)^{2}}{121} .
\end{gathered}
$$

Thus, when $t=t_{E X}, \Delta c \leq(2 / 3) A^{E}$ is the condition for both firms producing in equilibrium, which is consistent with $t_{E X} \leq t_{b 2}$, as is seen from (26). For $\Delta c>(2 / 3) A^{E}$, where only firm E supplies goods to the market, the optimal tariff is $t=t_{b 2}=A^{E} / 3$.

Moreover, as the FTA members' joint welfare is the sum of country A's consumer surplus, country A's tariff revenue, and firm I's profit in country B, the joint welfare when $t=t_{E X}$ is given by

$$
\begin{aligned}
W_{E X}^{A B}\left(t_{E X}\right) & =C S_{E X}^{A}\left(t_{E X}\right)+t_{E X} \times y_{E X}\left(t_{E X}\right)+\pi_{E X}^{I}\left(t_{E X}\right) \\
& =\frac{\left(7 A^{E}-5 \Delta c\right)^{2}}{242}+\frac{\left(A^{E}+4 \Delta c\right)\left(3 A^{E}+\Delta c\right)}{121}+\frac{4\left(2 A^{E}-3 \Delta c\right)^{2}}{121} .
\end{aligned}
$$

On the other hand, substituting Eq. (12) into Eq. (22), profits of the firms when $t=t_{b}$ are

$$
\pi_{E X}^{I}\left(t_{b}\right)=\frac{\left(10 A^{E}-17 \Delta c\right)^{2}}{576},
$$




$$
\pi_{E X}^{E}\left(t_{b}\right)=\frac{\left(2 A^{E}+5 \Delta c\right)^{2}}{144}
$$

In this case, the FTA members' joint welfare is given by

$$
\begin{aligned}
W_{E X}^{A B}\left(t_{b}\right) & =C S_{E X}^{A}\left(t_{b}\right)+t_{b} \times y_{E X}\left(t_{b}\right)+\pi_{E X}^{I}\left(t_{b}\right) \\
& =\frac{49\left(2 A^{E}-\Delta c\right)^{2}}{1152}+\frac{\left(2 A^{E}-\Delta c\right)\left(2 A^{E}+5 \Delta c\right)}{96}+\frac{\left(10 A^{E}-17 \Delta c\right)^{2}}{576} .
\end{aligned}
$$

From Eq. (30), the condition under which both firms produce goods in this equilibrium is $\Delta c \leq(10 / 17) A^{E} \approx 0.588 A^{E}$. As $t=t_{b}$ is chosen before formation of FTA when $\Delta c \leq(2 / 5) A^{E}$ (see Lemma 1 ), both firms produce goods in equilibrium in this parameter.

The above analysis yields the following lemma.

Lemma 2. After formation of FTA, country A's external tariffs are (i) $t=t_{E X}$ when $0<\Delta c \leq(14 / 43) A^{E}$; (ii) $t=t_{b}$ when $(14 / 43) A^{E}<\Delta c \leq(2 / 5) A^{E}$; (iii) $t=t_{E X}$ when (2/5) $A^{E}<\Delta c \leq(2 / 3) A^{E}$; and (iv) $t=t_{b 2}$ when (2/3) $A^{E}<\Delta c \leq A^{E}$. In (i)-(iii), both firms produce goods in equilibrium, and in (iv) only firm E produces goods.

The tariff schedule specified in Lemma 2 is shown in Figure 1. In this figure, $\Delta c$ is taken on the horizontal axis, and tariff level is taken on the vertical axis. In the figure, upward-sloping lines indicate $t=t_{E X}$ in (i) and (iii) of Lemma 2 and a downward-sloping line indicates $t=t_{b}$ in (ii) of Lemma 2. Also, a horizontal line indicates $t=t_{b 2}$ in (iv) of Lemma 4. Solid parts of those lines show the tariff schedule.

Note that, as firm I's profit is zero in (iv), $W^{A B}=W^{A}$. Thus, from Eq. (19) the FTA members' joint welfare is given by

$$
W_{E X}^{A B}\left(t_{b 2}\right)=\frac{\left(A^{E}\right)^{2}}{6} .
$$




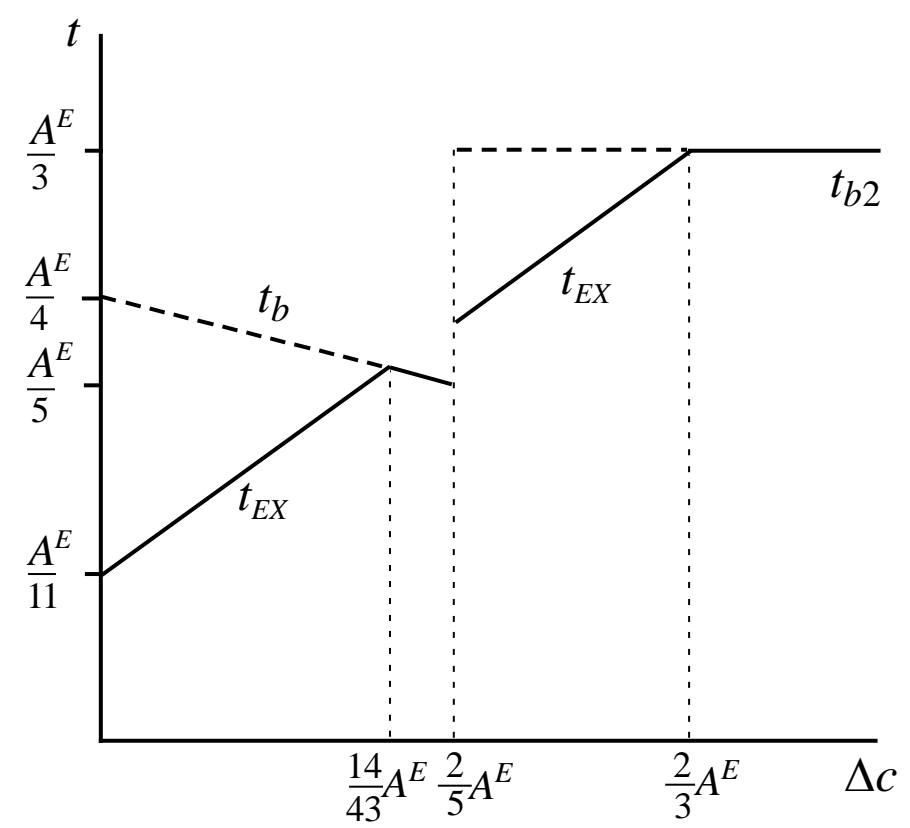

Figure 1. Country A's tariff schedule

\subsection{The Subgame in which Firm E Conducts FDI}

Next, we examine equilibrium at stage 4 of the game in a subgame in which Firm E chooses to conduct FDI at stage 3 to produce goods in compliance with the ROO. If firm E complies with the ROO, then both firms I and E can supply goods to country A's market tariff-free. However, firm E's production at a subsidiary located in country B will lead to technology spillovers from firm E to firm I, causing firm I's marginal costs to decline, depending on the extent of the production process shifted to the subsidiary through FDI.

As discussed in section 2, we assume a simple relationship of $\gamma=\phi$ between ROO $\phi \in[0,1]$ and the degree of technology spillovers $\gamma \in[0,1]$. Thus, we can conduct our analysis of policy variable $\phi$ and the degree of technology spillovers $\gamma$ that should vary with a change in $\phi$ without distinguishing between them. Thus, hereafter we express the degree of technological spillover by $\phi{ }^{4}$ In this case, the profit of each firm is given by

\footnotetext{
${ }^{4}$ More generally, an ROO will be chosen based on Eq. (2) so that a certain degree of spillovers which will be specified in the analysis below is realized. The analysis in this paper needs to be slightly modified if the degree of spillovers specified in the analysis is an interior solution but the level of $\phi$ required to achieve
} 


$$
\pi^{I}=\left(p-c^{I}+\phi \Delta c\right) x, \quad \pi^{E}=\left(p-c^{E}\right) y .
$$

From the first-order condition, the output of each firm in Nash equilibrium at stage 4 of the game is

$$
x_{F D I}=\left(A^{E}-2(1-\phi) \Delta c\right) / 3, \quad y_{F D I}=\left(A^{E}+(1-\phi) \Delta c\right) / 3,
$$

where the subscript FDI represents a variable for equilibrium in a subgame where firm E has chosen FDI. Furthermore, each firm's profit in a Nash equilibrium at stage 4 is

$$
\pi_{F D I}^{I}=\left(x_{F D I}\right)^{2}=\left(A^{E}-2(1-\phi) \Delta c\right)^{2} / 9, \quad \pi_{F D I}^{E}=\left(y_{F D I}\right)^{2}=\left(A^{E}+(1-\phi) \Delta c\right)^{2} / 9 .
$$

Clearly, firm E's profit is monotonically decreasing in $\phi$.

Since country A's tariff revenue disappears, the FTA members' joint welfare is the sum of firm I's profit and country A's consumer surplus:

$$
\begin{aligned}
W_{F D I}^{A B} & =C S_{F D I}^{A}+\pi_{F D I}^{I} \\
& =\frac{\left(2 A^{E}-(1-\phi) \Delta c\right)^{2}}{18}+\frac{\left(A^{E}-2(1-\phi) \Delta c\right)^{2}}{9} .
\end{aligned}
$$

As is evident from Eq. (37), $W_{F D I}^{A B}$ is a quadratic equation in $\phi$, with a positive coefficient for the $\phi^{2}$ term, $W_{F D I}^{A B}$ is a downward-convex function in $\phi$. Moreover, $\partial W_{F D I}^{A B} / \partial \phi=0$ yields $\phi_{1}=-\left(2 A^{E}-3 \Delta c\right) / 3 \Delta c$. Thus, for $\Delta c \leq(2 / 3) A^{E}, \quad \phi_{1} \leq 0$ holds and hence $W_{F D I}^{A B}$ is a monotonically increasing function of $\phi \in[0,1]$. On the other hand, for $\Delta c>(2 / 3) A^{E}$, from Eq. (35), $x_{F D I} \geq 0$ holds when $A^{E}-2(1-\phi) \Delta c \geq 0$ and hence

$$
\phi \geq 1-\frac{A^{E}}{2 \Delta c}
$$

must hold for $x_{F D I} \geq 0$. Thus, substituting $\Delta c>(2 / 3) A^{E}$ into the right hand side of the above inequality yields $\phi>1 / 4$. If $\phi \leq 1 / 4$, then $x_{F D I}=0$ holds. When $x_{F D I}=0$, it holds that $y_{F D I}=A^{E} / 2$. In this case, $W_{F D I}^{A B}$ becomes

$$
W_{F D I}^{A B}\left(x_{F D I}=0\right)=C S_{F D I}^{A}\left(x_{F D I}=0\right)=\frac{\left(A^{E}\right)^{2}}{8} \text {. }
$$

that level of spillovers exceeds one. Otherwise, our main results will not qualitatively change even in a more general setup. 
To investigate the maximum of $W_{F D I}^{A B}$, we only need to compare the values of $W_{F D I}^{A B}$ at $\phi<1 / 4, \phi=1 / 4$ and $\phi=1$. From Eq. (37), at $\phi=1 / 4$ and $\phi=1 W_{F D I}^{A B}$ is given by

$$
\begin{gathered}
W_{F D I}^{A B}\left(\phi=\frac{1}{4}\right)=\frac{\left(A^{E}\right)^{2}}{3}-\frac{A^{E} \Delta c}{2}+\frac{9}{32}(\Delta c)^{2}, \\
W_{F D I}^{A B}(\phi=1)=\frac{\left(A^{E}\right)^{2}}{3} .
\end{gathered}
$$

It is obvious that $W_{F D I}^{A B}\left(x_{F D I}=0\right)<W_{F D I}^{A B}(\phi=1)$. Moreover, we have

$$
W_{F D I}^{A B}\left(\phi=\frac{1}{4}\right)-W_{F D I}^{A B}(\phi=1)=-\frac{\Delta c}{2}\left(A^{E}-\frac{9}{16} \Delta c\right)<0
$$

because $\Delta c<A^{E}$. Therefore, even for $\Delta c>(2 / 3) A^{E}$ the FTA members' joint welfare is maximised at $\phi=1$.

\subsection{The Choice between Exports and FDI}

Next, we analyse firm E's choice of exports or FDI in stage 3 of the game. This analysis can be done by calculating the level of ROO that equalises firm E's profits when it chooses to export and those when it chooses to conduct FDI.

First, when firm E chooses to export and country A's external tariff is $t_{E X}$, which is given by Eq. (24), firm E's profits are given by Eq. (28). Taking this and firm E's profits when it makes FDI, which are given by Eq. (36), and solving $\pi_{E X}^{E}\left(t_{E X}\right)=\pi_{F D I}^{E}$ for $\phi$, we obtain

$$
\phi^{*} \equiv \frac{2\left(A^{E}+4 \Delta c\right)}{11 \Delta c}
$$

Thus, when the ROO is $\phi=\phi^{*}$, firm $\mathrm{E}$ is indifferent between exporting under $t=t_{E X}$ and FDI.

Next, when the tariff imposed by country A is $t_{b}$ (Eq. (12)) for firm E's choice of exporting, firm E's profits are given by Eq. (31). With this and firm E's profits under FDI, which are given by Eq. (36), we solve $\pi_{E X}^{E}\left(t_{b}\right)=\pi_{F D I}^{E}$ for $\phi$ to obtain

$$
\phi^{* *} \equiv \frac{2 A^{E}-\Delta c}{4 \Delta c} .
$$


Hence, when the ROO is $\phi=\phi^{* *}$, firm $\mathrm{E}$ is indifferent between exporting under $t=t_{b}$ and FDI.

From a similar analysis for the case in which country A's external tariff is $t_{b 2}$ (Eq. (17)) when firm E chooses exports, Eqs. (18) and (36) lead to

$$
\pi_{F D I}^{E}-\pi_{b 2}^{E}=\frac{\left(A^{E}+(1-\phi) \Delta c\right)^{2}}{9}-\frac{\left(A^{E}\right)^{2}}{9}=\frac{(1-\phi) \Delta c\left(2 A^{E}+(1-\phi) \Delta c\right)}{9} \geq 0 .
$$

Therefore, when country A's external tariff is $t=t_{b 2}$, firm $\mathrm{E}$ is indifferent between exports and FDI when the ROO is $\phi=1$, but it chooses FDI when the ROO is $\phi<1$.

The following lemma summarizes the above results.

Lemma 3. Given that the relationship between the ROO and the degree of technology spillovers from FDI is given by $\gamma=\phi$, (i) When country A's external tariff is $t=t_{E X}$, firm $E$ chooses FDI when the ROO is $\phi \leq \phi^{*}$, where $\phi^{*}$ is defined by (40), and chooses exports when the ROO is $\phi>\phi^{*}$; (ii) when country A's external tariff is $t=t_{b}$, firm $E$ chooses FDI when the ROO is $\phi \leq \phi^{* *}$, where $\phi^{* *}$ is defined by (41), and chooses exports when the ROO is $\phi>\phi^{* *}$; (iii) when country A's external tariff is $t=t_{b 2}$, firm $E$ chooses FDI for any ROO in the range of $\phi \in[0,1]$.

Note that, from Eq. (40), when

$$
\Delta c>(2 / 3) A^{E},
$$

$\phi^{*}<1$ holds and hence the optimal ROO is given by an interior solution. However, this case is excluded because $t_{E X}>t_{b 2}$ holds for $\Delta c>(2 / 3) A^{E}$, as shown in section 4.1. Similarly, from Eq. (41), when

$$
\Delta c>(2 / 5) A^{E},
$$

$\phi^{* *}<1$ holds and the optimal ROO becomes an interior solution. 


\section{OPTIMAL ROO AND TECHNOLOGY SPILLOVERS IN EQUILIBRIUM}

Based on the analysis in the previous sections, we derive the optimal ROO in stage 1 of the game and solve the entire model for the SPNE. We denote the optimal ROO in stage 1 by $\hat{\phi}$.

In the analysis below, we divide the range of $\Delta c$ into 4 segments. To find the optimal ROO that maximises the FTA members' joint welfare in each case, we conduct an analysis by taking into account firm E's choice between exports and FDI at stage 3 of the game, as shown in Lemma 3, and country A's external tariff at stage 2 of the game, as shown in Lemma 2.

Case 1: $0<\Delta c \leq(14 / 43) A^{E}$

In this case, from Lemma 2, country A imposes the external tariff of $t=t_{E X}$. From Lemma 3, firm $E$ chooses FDI if $\phi \leq \phi^{*}$. However, as $\Delta c<(2 / 3) A^{E}$ holds, (42) implies $\phi^{*}>1$ and hence firm $\mathrm{E}$ chooses FDI for any $\phi \in[0,1]$. Furthermore, since from Eq. (37) $W_{F D I}^{A B}$ is monotonically increasing in $\phi$ in this case, it is optimal for the FTA members to choose the maximum possible $\phi$. That is, $\hat{\phi}=1$. We need to check whether the joint welfare of the FTA members at $\hat{\phi}=1$ is greater than that in the case where firm E exports. From Eq. (37), the joint welfare of countries A and B at $\hat{\phi}=1$ is

$$
W_{F D I}^{A B}(\hat{\phi}=1)=\frac{\left(2 A^{E}\right)^{2}}{18}+\frac{\left(A^{E}\right)^{2}}{9}=\frac{\left(A^{E}\right)^{2}}{3} .
$$

Using Eq. (29), it follows that

$$
W_{F D I}^{A B}(\hat{\phi}=1)-W_{E X}^{A B}\left(t_{E X}\right)=\frac{\left(A^{E}\right)^{2}}{3}-\left[\frac{\left(7 A^{E}-5 \Delta c\right)^{2}}{242}+\frac{\left(A^{E}+4 \Delta c\right)\left(3 A^{E}+\Delta c\right)}{121}+\frac{4\left(2 A^{E}-3 \Delta c\right)^{2}}{121}\right]
$$

which implies that $W_{F D I}^{A B}(\hat{\phi}=1)<W_{E X}^{A B}\left(t_{E X}\right)$ holds when

$$
\Delta c<((70-11 \sqrt{35}) / 105) A^{E} \approx 0.047 A^{E}, \quad \text { or } \quad \Delta c>((70+11 \sqrt{35}) / 105) \approx 1.29 A^{E} \text {, }
$$

and $W_{F D I}^{A B}(\hat{\phi}=1) \geq W_{E X}^{A B}\left(t_{E X}\right)$ holds when 


$$
((70-11 \sqrt{35}) / 105) A^{E} \leq \Delta c \leq((70+11 \sqrt{35}) / 105) A^{E} .
$$

As this case is restricted to the range of $0<\Delta c \leq(14 / 43) A^{E}$, it follows that $W_{F D I}^{A B}(\hat{\phi}=1)<W_{E X}^{A B}\left(t_{E X}\right) \quad$ holds when $\Delta c<((70-11 \sqrt{35}) / 105) A^{E} \quad$, and $W_{F D I}^{A B}(\hat{\phi}=1) \geq W_{E X}^{A B}\left(t_{E X}\right)$ holds when $((70-11 \sqrt{35}) / 105) A^{E} \leq \Delta c \leq(14 / 43) A^{E}$.

Therefore, in equilibrium, firm E shifts its entire production process for the country A's market to its plant in country B, thereby causing technology spillovers from firm E to firm I so that both firms' marginal costs are equalised. In equilibrium, both firms produce goods. However, since the gains from technology spillovers are small when $\Delta c$ is small, the joint welfare of the FTA members becomes higher when firm E exports due to tariff revenues. Nevertheless, when $\Delta c$ is small, the loss for firm $\mathrm{E}$ from spillovers is also small and hence firm E chooses FDI even under the most stringent ROO (i.e., $\phi=1$ ). Consequently, the FTA members have to accept lower welfare under the FDI regime when $\Delta c<((70-11 \sqrt{35}) / 105) A^{E}$. Otherwise, the FTA members enjoy higher welfare under the FDI regime with $\hat{\phi}=1$.

Case 2: $(14 / 43) A^{E}<\Delta c \leq(2 / 5) A^{E}$

In the second case, country A chooses the external tariff of $t=t_{b}$ (Lemma 2). Firm E chooses FDI if $\phi \leq \phi^{* *}$ (Lemma 3). However, since $\Delta c \leq(2 / 5) A^{E}$ in this case, (43) implies that $\phi^{* *} \geq 1$. Thus, as in the first case, firm E chooses FDI for any $\phi \in[0,1]$. As it is optimal for the FTA members to choose the maximum possible $\phi$, they choose $\hat{\phi}=1$. As in Case 1 , we check whether the joint welfare of the FTA members at $\hat{\phi}=1$ is greater than when firm E choses to export. From Eq. (32), we have

$$
W_{F D I}^{A B}(\hat{\phi}=1)-W_{E X}^{A B}\left(t_{b}\right)=\frac{\left(A^{E}\right)^{2}}{3}-\left[\frac{49\left(2 A^{E}-\Delta c\right)^{2}}{1152}+\frac{\left(2 A^{E}-\Delta c\right)\left(2 A^{E}+5 \Delta c\right)}{96}+\frac{\left(10 A^{E}-17 \Delta c\right)^{2}}{576}\right]
$$

It then follows that $W_{F D I}^{A B}(\hat{\phi}=1) \geq W_{E X}^{A B}\left(t_{b}\right)$ holds when

$$
((130-8 \sqrt{205}) / 189) A^{E} \approx 0.082 A^{E} \leq \Delta c \leq((130+8 \sqrt{205}) / 189) A^{E} \approx 1.29 A^{E} .
$$

Recall that Case 2 corresponds to the range of $(14 / 43) A^{E}<\Delta c \leq(2 / 5) A^{E}$, it follows that $W_{F D I}^{A B}(\hat{\phi}=1) \geq W_{E X}^{A B}\left(t_{b}\right)$ always holds in this case. 
Thus, the outcome in the SPNE is the same as in Case 1. The equilibrium joint welfare of the FTA members in the FDI regime is higher than that when firm E chooses to export.

Case 3: $(2 / 5) A^{E}<\Delta c \leq(2 / 3) A^{E}$

In the third case, country A again imposes the external tariff of $t=t_{E X}$ (Lemma 2). In addition, because $\Delta c \leq(2 / 3) A^{E}$ in this case, the outcome is essentially the same as in Case 1. Given the parameters of this case and using the analysis of Case 1, the joint welfare of the FTA members is always greater when firm E chooses FDI in equilibrium than when it chooses exports.

Case 4: $(2 / 3) A^{E}<\Delta c \leq A^{E}$

In this final case, country A chooses the external tariff of $t=t_{b 2}$ (Lemma 2). Firm E always chooses FDI for any $\phi \in[0,1]$ (Lemma 3). As analysed in section 4.2, $W_{F D I}^{A B}$ is maximised at $\phi=1$. In addition, in the case where only firm E supplies goods, comparing the joint welfare of the FTA members when firm E supplies goods tariff-free due to FDI with that when it supplies goods by exporting, the case of FDI is never the optimal because welfare is higher in the latter case in which tariff revenue is earned. On the other hand, as long as $\phi=1$, it is never the case in which only firm E supplies goods in equilibrium.

Thus, we only need to compare the joint welfare of the FTA members in the equilibrium where firm E chooses FDI at $\phi=1$ and that in the equilibrium where only firm E supplies goods by exports under $t=t_{b 2}$. From Eqs. (33) and (39), it follows that

$$
W_{F D I}^{A B}(\phi=1)-W_{E X}^{A B}\left(t_{b 2}\right)=\frac{\left(A^{E}\right)^{2}}{3}-\frac{\left(A^{E}\right)^{2}}{6}=\frac{\left(A^{E}\right)^{2}}{6}>0,
$$

implying that the members' welfare is greater in the FDI regime.

From the above analysis, we obtain the following proposition. 
Proposition 1. When the relationship between the ROO and the degree of technology spillovers from FDI is given by $\gamma=\phi$, it is an SPNE that $\hat{\phi}=1$ is chosen by countries A and $B$ at stage 1, the external tariffs specified in Lemma 2 are chosen by country $A$ at stage 2, and firm E chooses to conduct FDI so that the ROO is satisfied at stage 3. Thus, in equilibrium, technology spillovers from firm E to firm I are perfect, and both firms produce the same amount of goods.

Therefore, the most stringent ROO is always imposed in equilibrium. Country A's external tariff is adjusted depending on the parameter value. Despite the fact that the most stringent ROO is imposed and technology spillovers from firm E to firm I are perfect, firm E chooses FDI to comply with the ROO and shifts its entire production process for goods supplied to the country A's market to a plant in country B.

Note that, although the joint welfare of the FTA members in equilibrium is at its highest level when $\Delta c \geq((70-11 \sqrt{35}) / 105) A^{E}$, it is higher in the case where firm $\mathrm{E}$ exports when $\Delta c<((70-11 \sqrt{35}) / 105) A^{E}$. Nevertheless, the higher level of welfare under exports by firm $\mathrm{E}$ cannot be achieved in equilibrium in the latter case.

\section{THE EFFECTS OF MULTILATERAL NEGOTIATION FOR TRADE LIBERALISATION BEFORE FORMATION OF FTA}

In the previous section, we found that the most stringent ROO is imposed in equilibrium, which requires that the entire production process be conducted in the FTA's member countries for the produced goods to be qualified for tariff-free transactions. As a result, complete technology spillovers of firm E's superior technology to firm I occur through FDI; notwithstanding, firm E chooses to conduct FDI in equilibrium.

This result seems to be somewhat unrealistic. One factor leading to this unrealistic result is a high degree of freedom for country A in the choice of the tariffs up to the optimal level before formation of FTA. In the real world, however, major countries may not be able to impose the optimal tariffs before formation of FTA, because of the 
multilateral negotiations for trade liberalisation after the World War II at GATT/WTO. Thus, we next examine how the results in the previous sections will change if the tariff ceiling is set before formation of FTA due to multilateral negotiation for trade liberalisation.

Let $\lambda \in[0,1]$ be the measure of the "degree of trade liberalisation.” $\lambda=0$ means no trade liberalisation and $\lambda=1$ means complete trade liberalisation. Then, as shown in Lemma 1, before formation of FTA country A imposes $t=t_{b}$ when $\Delta c \leq(2 / 5) A^{E}$ and $t=t_{b 2}$ when $(2 / 5) A^{E}<\Delta c \leq A^{E}$. Those tariffs are reduced by $(1-\lambda)$ as a result of multilateral negotiation for trade liberalisation. That is, we assume that country A can only impose tariffs $t=(1-\lambda) t_{b}$ or $t=(1-\lambda) t_{b 2}$ :

Assumption 1. Because of multilateral negotiation for trade liberalisation, country A can only impose $t=(1-\lambda) t_{b}$ or $t=(1-\lambda) t_{b 2}$ before it enters the FTA, where $\lambda \in[0,1]$ indicates the degree of trade liberalisation.

Note that under $t=(1-\lambda) t_{b}$, it is shown from Eq. (8) that $x_{b}=0$ when

$$
\Delta c>\frac{2(3+\lambda)}{15+\lambda} A^{E}
$$

It is straightforward to show that

$$
\frac{\mathrm{d}}{\mathrm{d} \lambda}\left(\frac{2(3+\lambda)}{15+\lambda}\right)=\frac{24}{(15+\lambda)^{2}}>0
$$

Thus, for $\lambda>0$, there exists a range of $\Delta c$ for which country A imposes $t=t_{b 2}$ before the trade liberalisation but switches to $t=(1-\lambda) t_{b}<(1-\lambda) t_{b 2}$ after the trade liberalisation. Country A imposes $t=(1-\lambda) t_{b 2}$ when (44) holds and $t=(1-\lambda) t_{b}$ otherwise.

Under Assumption 1, country A's external tariffs after formation of the FTA partially change. From Eqs. (12) and (24), $t_{E X}>(1-\lambda) t_{b}$ holds when

$$
\Delta c>\frac{14-22 \lambda}{43-11 \lambda} A^{E} .
$$


Similarly, from Eqs. (17) and (24), $t_{E X}>(1-\lambda) t_{b 2}$ holds when

$$
\Delta c>\frac{8-11 \lambda}{12} A^{E}
$$

It can be shown that

$$
\frac{8-11 \lambda}{12} \geq \frac{2(3+\lambda)}{15+\lambda}
$$

holds if and only if

$$
\lambda \leq \frac{-181+\sqrt{34873}}{22} \approx 0.261 .
$$

Moreover, $t_{E X}>(1-\lambda) t_{b}$ holds at $\Delta c=0$ if and only if $\lambda>7 / 11 \approx 0.636$. If that is the case, country A can never choose $t=t_{E X}$.

Then, we obtain the following lemma.

Lemma 4. Impose Assumption 1. (A) For $\lambda \in\left[0, \frac{7}{11}\right]$ country A's external tariff after formation of the FTA is (i) $t=t_{E X}$ when $0<\Delta c \leq\{(14-22 \lambda) /(43-11 \lambda)\} A^{E}$, (ii) $t=(1-\lambda) t_{b}$ when $\{(14-22 \lambda) /(43-11 \lambda)\} A^{E}<\Delta c \leq\{2(3+\lambda) /(15+\lambda)\} A^{E}$, (iii) $t=t_{E X}$ when $\{2(3+\lambda) /(15+\lambda)\} A^{E} \quad<\Delta c \leq\{(8-11 \lambda) / 12\} A^{E}$, and (iv) $t=(1-\lambda) t_{b 2} \quad$ when $\{(8-11 \lambda) / 12\} A^{E}<\Delta c \leq A^{E}$. Case (iii) exists only if (47) holds. (B) For $\lambda \in\left(\frac{7}{11}, 1\right]$ country A's external tariff after formation of the FTA is (i) $t=(1-\lambda) t_{b}$ when $0<\Delta c \leq\{2(3+\lambda) /(15+\lambda)\} A^{E}$ and (ii) $t=(1-\lambda) t_{b 2}$ when $\{2(3+\lambda) /(15+\lambda)\} A^{E}<\Delta c \leq A^{E}$.

The tariff schedule specified in part (A) of Lemma 4 is depicted in Figure 2. As shown in the figure, under Assumption 1, the tariff ceiling is reduced to $(1-\lambda) t_{b}$ and $(1-\lambda) t_{b 2}$. The tariff schedule consists of four parts. The thick solid lines indicate the actual tariff schedule under Assumption 1. 


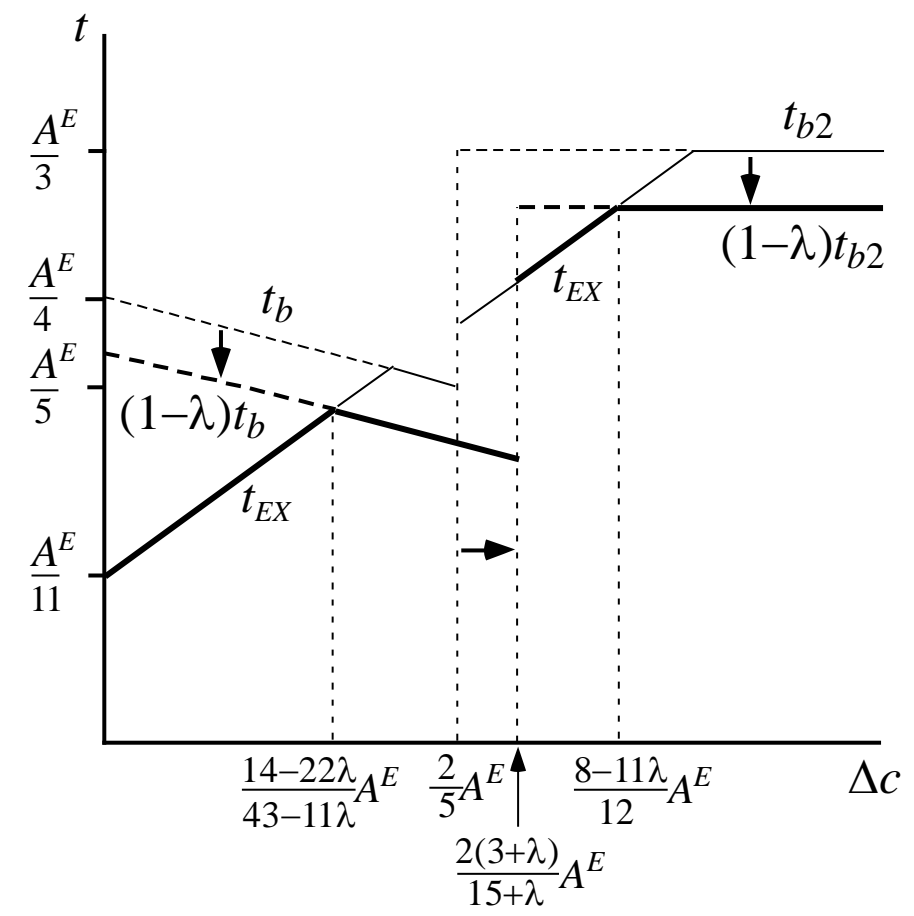

Figure 2. Country A's tariff schedule under Assumption 1 for $\lambda \in\left[0, \frac{7}{11}\right]$

Based on the tariff schedule in Lemma 4, we examine how the results in section 5 change under Assumption 1. In part (A) of Lemma 4, (i) and (iii) respectively correspond to Case 1 or Case 3 in section 5. Basically, there is no change in either case. Thus, we only need to analyse (ii) and (iv) in part (A) and (i) and (ii) in part B of Lemma 4.

First, we derive the levels of ROO for which firm E is indifferent between FDI and exporting when country A's external tariff is either $t=(1-\lambda) t_{b}$ or $t=(1-\lambda) t_{b 2}$. From $\pi_{E X}^{E}\left((1-\lambda) t_{b}\right)=\pi_{F D I}^{E}$, using Eqs. (9), (12), and (36), we obtain

$$
\phi^{* *}(\lambda) \equiv(1-\lambda)\left(\frac{2 A^{E}-\Delta c}{4 \Delta c}\right) .
$$

Similarly, from Eqs. (16), (17), and (36), it yields that

$$
\begin{aligned}
\pi_{F D I}^{E}-\pi_{E X}^{E}\left((1-\lambda) t_{b 2}\right) & =\frac{\left(A^{E}+(1-\phi) \Delta c\right)^{2}}{9}-\frac{\left((2+\lambda) A^{E}\right)^{2}}{36} \\
& =-\frac{\left\{(4+\lambda) A^{E}+2(1-\phi) \Delta c\right\}\left\{\left(\lambda A^{E}-2(1-\phi) \Delta c\right\}\right.}{36},
\end{aligned}
$$

which implies that $\pi_{E X}^{E}\left((1-\lambda) t_{b 2}\right)=\pi_{F D I}^{E}$ holds if 


$$
\phi^{* * *}(\lambda) \equiv 1-\frac{\lambda A^{E}}{2 \Delta c} \leq 1
$$

In the following lemma, we show that $\phi^{* *}(\lambda)$ can be an interior solution.

Lemma 5. For $A^{E} / 6<\Delta c$, (i) there exists $\lambda \in\left(0, \frac{7}{11}\right]$ for which $\phi^{* *}(\lambda)<1$ holds and (ii) $\phi^{* *}(\lambda)<1$ holds for all $\lambda \in\left(\frac{7}{11}, 1\right]$.

Proof. (i) From (48), $\phi^{* *}(\lambda)<1$ holds if and only if

$$
\frac{2 A^{E}-5 \Delta c}{2 A^{E}-\Delta c}<\lambda
$$

It is straightforward to show that $\left(2 A^{E}-5 \Delta c\right) /\left(2 A^{E}-\Delta c\right)<7 / 11$ holds if and only if $A^{E} / 6<\Delta c$. From Lemma 4, Country A chooses $t=(1-\lambda) t_{b}$ when $\{(14-22 \lambda) /(43-11 \lambda)\} A^{E}<\Delta c \leq\{2(3+\lambda) /(15+\lambda)\} A^{E}$. For $\lambda=0,(14-22 \lambda) /(43-11 \lambda)=14 / 43$ $>1 / 6$. Thus, when $A^{E} / 6<\Delta c$, there must exist $\lambda \in\left(0, \frac{7}{11}\right]$ for which $\phi^{* *}(\lambda)<1$ holds.

(ii) For $\lambda \in\left(\frac{7}{11}, 1\right]$, from (48) it follows that

$$
\begin{aligned}
\phi^{* *}(\lambda) \equiv(1-\lambda)\left(\frac{2 A^{E}-\Delta c}{4 \Delta c}\right) & <\frac{4}{11}\left(\frac{2 A^{E}-\Delta c}{4 \Delta c}\right) \\
& =\frac{2 A^{E}-\Delta c}{11 \Delta c} .
\end{aligned}
$$

Then, it can be shown that $\left(2 A^{E}-\Delta c\right) /(11 \Delta c) \leq 1$ holds if and only if $A^{E} / 6 \leq \Delta c$.

Then, firm E chooses either FDI or exports as shown in the following lemma.

Lemma 6. Assume that the relationship between the ROO and the degree of technology spillovers from FDI is given by $\gamma=\phi$. Under Assumption 1, after formation of the FTA (i) when country A's external tariff is $t=(1-\lambda) t_{b}$ if the ROO is $\phi \leq \phi^{* *}$, where $\phi^{* *}$ is defined by Eq. (48), firm E chooses FDI, and if it is $\phi>\phi^{* *}$, firm E chooses exports. 
(ii) when country A's external tariff ist $=(1-\lambda) t_{b 2}$, if the ROO is $\phi \leq \phi^{* * *}$, where $\phi^{* * *}$ is defined by Eq. (49), firm E chooses FDI, and if it is $\phi>\phi^{* * *}$, firm E chooses exports.

Based on the above observations, we next examine the optimal ROO $\hat{\phi}$. First, when $\hat{t}=(1-\lambda) t_{b}$, the joint welfare of the FTA members in the case where firm $\mathrm{E}$ exports $W_{E X}^{A B}\left((1-\lambda) t_{b}\right)$ is given by

$$
\begin{aligned}
W_{E X}^{A B}\left((1-\lambda) t_{b}\right) & =\frac{(7+\lambda)^{2}\left(2 A^{E}-\Delta c\right)^{2}}{1152}+\frac{(1-\lambda)\left(2 A^{E}-\Delta c\right)\left\{2 A^{E}+5 \Delta c+\lambda\left(2 A^{E}-\Delta c\right)\right\}}{96} \\
& +\frac{\left\{10 A^{E}-17 \Delta c-\lambda\left(2 A^{E}-\Delta c\right)\right\}^{2}}{576} .
\end{aligned}
$$

On the other hand, substituting Eq. (48) into Eq. (37) and recalculating, the joint welfare of the FTA members $W_{F D I}^{A B}\left(\hat{\phi}=\phi^{* *}(\lambda)\right)$ under $\phi=\phi^{* *}$ in the case where firm $\mathrm{E}$ conducts FDI to comply with the ROO is given by

$$
W_{F D I}^{A B}\left(\hat{\phi}=\phi^{* *}(\lambda)\right)=\frac{\left(A^{E}\right)^{2}\left(3 \lambda^{2}-14 \lambda+19\right)}{24}-\frac{A^{E} \Delta c(5-\lambda)(7-3 \lambda)}{24}+\frac{(\Delta c)^{2}(5-\lambda)^{2}}{32} .
$$

Comparing $W_{F D I}^{A B}\left(\hat{\phi}=\phi^{* *}(\lambda)\right)$ with $W_{E X}^{A B}\left((1-\lambda) t_{b}\right)$, it follows that

$$
W_{F D I}^{A B}\left(\hat{\phi}=\phi^{* *}(\lambda)\right)-W_{E X}^{A B}\left((1-\lambda) t_{b}\right)=\frac{(1-\lambda)\left(2 A^{E}-\Delta c\right)\left\{26 A^{E}-37 \Delta c-5 \lambda\left(2 A^{E}-\Delta c\right)\right\}}{128} .
$$

It can be shown that $W_{F D I}^{A B}\left(\hat{\phi}=\phi^{* *}(\lambda)\right)>W_{E X}^{A B}\left((1-\lambda) t_{b}\right)$ holds if and only if

$$
\Delta c<\frac{26-10 \lambda}{37-5 \lambda} A^{E}
$$

Note that $\hat{t}=(1-\lambda) t_{b}$ holds only for $\Delta c \leq\{2(3+\lambda) /(15+\lambda)\} A^{E}$. It follows that

$$
\frac{26-10 \lambda}{37-5 \lambda}-\frac{2(3+\lambda)}{15+\lambda}=\frac{168(1-\lambda)}{(37-5 \lambda)(15+\lambda)}>0 \text {. }
$$

Thus, for all range of $\Delta c$ for which $\hat{t}=(1-\lambda) t_{b}, W_{F D I}^{A B}\left(\hat{\phi}=\phi^{* *}(\lambda)\right)>W_{E X}^{A B}\left((1-\lambda) t_{b}\right)$ holds.

Next, when $\hat{t}=(1-\lambda) t_{b 2}$, the joint welfare of the FTA members in the case where firm $E$ exports $W_{E X}^{A B}\left((1-\lambda) t_{b 2}\right)$ is given by 


$$
W_{E X}^{A B}\left((1-\lambda) t_{b 2}\right)=\frac{\left(A^{E}\right)^{2}(2-\lambda)(2+\lambda)}{24} .
$$

On the other hand, as Eq. (35) indicates that $x=A^{E}(1-\lambda) / 3>0$ holds for $\phi=\phi^{* * *}(\lambda)$, substituting Eq. (49) into Eq. (37) and recalculating, the joint welfare of the FTA members $W_{F D I}^{A B}\left(\hat{\phi}=\phi^{* * *}(\lambda)\right)$ is given by

$$
W_{F D I}^{A B}\left(\hat{\phi}=\phi^{* * *}(\lambda)\right)=\frac{\left(A^{E}\right)^{2}}{24}\left(3 \lambda^{2}-8 \lambda+8\right) .
$$

It is shown that

$$
W_{F D I}^{A B}\left(\hat{\phi}=\phi^{* * *}(\lambda)\right)-W_{E X}^{A B}\left((1-\lambda) t_{b 2}\right)=\frac{\left(A^{E}\right)^{2}}{6}(1-\lambda)^{2} \geq 0 .
$$

Thus, FTA members' joint welfare is higher when firm E conducts FDI under $\phi=\phi^{* * *}(\lambda)$ than when firm E exports.

Finally, from the analysis in section 4.2 , we know that $W_{F D I}^{A B}$ is a monotonically increasing function of $\phi$ for $\Delta c \leq(2 / 3) A^{E}$, but it may not be monotonic for $\Delta c>(2 / 3) A^{E}$. Thus, for $\Delta c>(2 / 3) A^{E}$, we need to check whether $W_{F D I}^{A B}$ reaches its maximum at $\phi=\phi^{* * *}(\lambda)$ in all admissible range of $\phi$ with being consistent with FDI by firm E. From Eqs. (38) and (52), it follows that

$$
W_{F D I}^{A B}\left(\hat{\phi}=\phi^{* * *}(\lambda)\right)-W_{F D I}^{A B}\left(\phi=\frac{1}{4}\right)=\frac{\left(3 \Delta c-2 \lambda A^{E}\right)\left\{2 A^{E}(8-3 \lambda)-9 \Delta c\right\}}{96} .
$$

Then, $\quad \Delta c \geq(2 / 3) \lambda A^{E}$ holds because $\Delta c>(2 / 3) A^{E}$ and $2 A^{E}(8-3 \lambda)-9 \Delta c>0$ holds because $A^{E}>\Delta c .^{5}$ Therefore, $W_{F D I}^{A B}\left(\hat{\phi}=\phi^{* * *}(\lambda)\right)-W_{F D I}^{A B}\left(\phi=\frac{1}{4}\right) \geq 0$ holds.

The above analysis is summarized in the following proposition.

Proposition 2. Impose Assumption 1. (A) For $\lambda \in\left[0, \frac{7}{11}\right]$, (i) when $0<\Delta c \leq\{(14-22 \lambda) /(43-11 \lambda)\} A^{E}$, the result is the same as that in Proposition 1. (ii) When $\{(14-22 \lambda) /(43-11 \lambda)\} A^{E}<\Delta c \leq\{2(3+\lambda) /(15+\lambda)\} A$, an SPNE is that $\hat{\phi}=\phi^{* *}(\lambda) \leq 1$ is

\footnotetext{
${ }^{5}$ Note that from Eq. (49), for $\Delta c \geq(2 / 3) \lambda A^{E}$, it follows that $\phi^{* * *}(\lambda) \geq 1 / 4$.
} 
chosen at stage 1 , country A chooses $\hat{t}=(1-\lambda) t_{b}$ at stage 2, firm E conducts FDI to comply with the ROO at stage 3. (iii) When $\{2(3+\lambda) /(15+\lambda)\} A^{E}<\Delta c \leq\{(8-11 \lambda) / 12\} A^{E}$, the result is again the same as that in Proposition 1. (iv) When $\{(8-11 \lambda) / 12\} A^{E}<\Delta c \leq A^{E}$, an SPNE is that $\hat{\phi}=\phi^{* * *}(\lambda)<1$ is chosen at stage 1 , country A chooses $\hat{t}=(1-\lambda) t_{b 2}$ at stage 2, and firm E conducts FDI to comply with the ROO at stage 3. Case (iii) exists only if (47) holds. (B) For $\lambda \in\left(\frac{7}{11}, 1\right]$, (i) when $0<\Delta c \leq\{2(3+\lambda) /(15+\lambda)\} A,{ }^{E}$ an SPNE is

that $\hat{\phi}=\phi^{* *}(\lambda)<1$ is chosen at stage 1 , country A chooses $\hat{t}=(1-\lambda) t_{b}$ at stage 2 , firm $E$ conducts FDI to comply with the ROO at stage 3. (ii) When $\{2(3+\lambda) /(15+\lambda)\} A^{E}<\Delta c \leq A^{E}$, an SPNE is the same as that in (iv) in part (A).

Therefore, by restricting the maximum tariff that country A can impose before formation of FTA, firm E still conducts FDI to comply with the ROO in equilibrium. Unlike Proposition 1, however, the optimal ROO may require only a part of the production process to be conducted within the FTA to comply with the ROO and hence the technology spillovers from firm E to firm I due to FDI is not perfect. In other words, the outcome becomes more realistic. In particular, if the degree of trade liberalisation before formation of the FTA is sufficiently high, the optimal ROO is always lower than the most stringent level. Moreover, from (48) and (49) it is obvious that both $\phi^{* *}(\lambda)$ and $\phi^{* * *}(\lambda)$ are decreasing in $\lambda$. That is, the optimal ROO becomes less stringent as trade is more liberalized before the FTA is formed. This is an important prediction from our model.

\section{CONCLUSION}

This study analysed the optimal choice of ROO by members of an FTA and the choice of the external tariffs by one member country in a three-country model with international duopoly when FDI by an external firm causes technology spillovers to an internal firm. To comply with the ROO of the FTA for supplying goods as qualified for tariff-free transaction, the external firm must undertake FDI into the FTA so that part or 
all of its production process takes place within the FTA. However, when the external firm's production technology is superior to that of rival internal firms, the FDI leads to technology spillovers to internal firms, depending on the extent of the production process that has been relocated. In this situation, the external firm must choose either to avoid technology spillovers to other firms by paying high tariffs (i.e., by exporting) or to comply with the ROO in spite of technology spillovers (i.e., FDI). Our study demonstrated that the external firm chooses to conduct FDI to comply with the ROO in equilibrium, though the most stringent ROO is imposed in the sense that a shift of the entire production process is required to comply with it, which causes perfect technology spillovers. Moreover, we also showed that if the tariff rate is restricted in prior to formation of the FTA by multilateral trade agreements, the optimal ROO may become an interior solution. In particular, if the degree of trade liberalisation in prior to formation of the FTA is sufficiently high, the optimal ROO is necessarily lower than the most stringent level.

An important implication from our analysis is that as trade is multilaterally more liberalized before FTAs are formed, ROO in FTAs tend to be less stringent. Given that the extent of multilateral trade liberalisation can be measured by the average level of most-favored nation (MFN) tariffs, our analysis predicts a positive correlation between the average MFN tariffs and the stringency of ROO in FTAs. Since our analysis focused on the issue of attracting inward FDI from the outside of FTAs and technology spillovers through FDI, the prediction from our analysis will be more relevant to FTAs among developing countries.

However, our model may be too simple to analyse the relationship between the degree of multilateral trade liberalisation in prior to formation of FTAs and the stringency of ROO. In our future work, we will enrich our model by incorporating other aspects of FTAs and examine relative importance of various factors in the optimal choice of ROO. 


\section{REFERENCES}

Belderbos RA, Sleuwaegen L (1997) Local Content Requirements and Vertical Market Structure. European Journal of Political Economy 13, 101-119.

Chang YM, Xiao R (2013) Free Trade Areas, the Limit of Rules of Origin, and Optimal Tariff Reductions under International Oligopoly: A Welfare Analysis. Journal of International Trade \& Economic Development 22, 694-728.

Davidson C, Matusz SJ, Kreinin M (1985) Analysis of Performance Standards for Direct Foreign Investments. Canadian Journal of Economics 18, 876-890.

Falvey R, Reed G (2002) Rules of origin as Commercial Policy Instruments. International Economic Review 43, 393-407.

Grossman G (1981) The Theory of Domestic Content Protection and Content Preference. Quarterly Journal of Economics 68, 584-603.

Haskel JE, Pereira, SC, Slaughter, MJ (2007) Does Inward Foreign Direct Investment Boost the Productivity of Domestic Firms? Review of Economics and Statistics 89, 482-496.

Ishikawa J, Mukunoki H, Mizoguchi Y (2007) Economic Integration and Rules of Origin under International Oligopoly. International Economic Review 48, 185-210.

Jinji N, Mizoguchi Y (2015) Optimal Rules of Origin with Asymmetric Compliance Costs under International Duopoly. Journal of Industry, Competition and Trade, online first. DOI: 10.1007/s10842-015-0202-z.

Ju J, Krishna K (2005) Firm Behaviour and Market Access in a Free Trade Area with Rules of Origin. Canadian Journal of Economics 38, 290-308.

Keller W. (2004) International Technology Diffusion. Journal of Economic Literature 42, 752-782.

Keller W, Yeaple SR (2009) Multinational Enterprises, International Trade, and Productivity Growth: Firm Level Evidence from the United States. Review of Economics and Statistics 91, 821-831.

Krishna K, Itoh M (1988) Content Protection and Oligopolistic Interactions. Review of Economic Studies 55, 107-125. 
Krishna K, Krueger AO (1995) Implementing Free Trade Agreements: Rules of Origin and Hidden Protection. In: Deardorff AV, Levinsohn J, Stern RM (eds) New Directions in Trade Theory, pp. 149-187. University of Michigan Press.

Krueger AO (1999) Free Trade Agreements as Protectionist Devices: Rules of Origin. In: Melvin JR, Moore JC, Riezman R (eds) Trade, Theory and Econometrics: Essays in Honor of John Chipman, pp. 91-101. Routledge Press, London.

Lahiri S, Ono Y (1998) Foreign Direct Investment, Local Content Requirement, and Profit Taxation. Economic Journal 108, 444-457.

Lahiri S, Ono Y (2003) Export-oriented Foreign Direct Investment and Local Content Requirement. Pacific Economic Review 8, 1-14.

Lopez-de-Silanes F, Markusen JR, Rutherford TF (1996) Trade Policy Subtleties with Multinational Firms. European Economic Review 40, 1605-1627.

Mukunoki H (2013) On the Welfare Effects of FTAs in the Presence of FDIs and Rules of Origin. RIETI Discussion Paper Series No. 13-E-053.

Qiu LD, Tao Z (2001) Export, Foreign Direct Investment, and Local Content Requirement. Journal of Development Economics 66, 101-125.

Takauchi K (2011) Rules of Origin and International R\&D Rivalry. Economics Bulletin 31, 2319-2332.

Takechi K, Kiyono K (2003) Local Content Protection: Specific-factor Model for Intermediate Goods Production and Market Segmentation. Japan and the World Economy 15, 69-87. 